\title{
Características de la estructura molecular de las proteínas E del virus del Zika y E1 del virus de la rubéola y posibles implicaciones en el neurotropismo y en las alteraciones del sistema nervioso
}

\author{
Luis Alberto Gómez ${ }^{1,2}$, Gladis Montoya1 ${ }^{1}$, Hernán Mauricio Rivera ${ }^{1,3}$, Juan Carlos Hernández ${ }^{1}$ \\ 1 Grupo de Fisiología Molecular, Subdirección de Investigación Científica y Tecnológica, Dirección de \\ Investigación en Salud Pública, Instituto Nacional de Salud, Bogotá, D.C., Colombia \\ 2 Departamento de Ciencias Fisiológicas, Facultad de Medicina, Universidad Nacional de Colombia, Bogotá, D.C., \\ Colombia \\ 3 Programa de Doctorado en Ciencias Biomédicas, Facultad de Medicina, Universidad Nacional de Colombia, \\ Bogotá, D.C., Colombia
}

Introducción. El virus del Zika (ZIKV) es un flavivirus con envoltura, transmitido a los seres humanos principalmente por el vector Aedes aegypti. La infección por ZIKV se ha asociado con un gran neurotropismo y con efectos neuropáticos, como el síndrome de Guillain-Barré en el adulto y la microcefalia fetal y posnatal, así como con un síndrome de infección congénita similar al producido por el virus de la rubéola (RV).

Objetivo. Comparar las estructuras moleculares de la proteína de envoltura E del virus del Zika (E-ZIKV) y de la E1 del virus de la rubéola (E1-RV), y plantear posibles implicaciones en el neurotropismo y en las alteraciones del sistema nervioso asociadas con el ZIKV.

Materiales y métodos. La secuencia de aminoácidos de la proteína E-ZIKV (PDB: 5iZ7) se alineó con la de la glucopreteína E1 del virus de la rubéola (PDB: 4ADG). Los elementos de la estructura secundaria se determinaron usando los programas Vector NTI Advance ${ }^{\circledR}$, DSSP y POSA, así como herramientas de gestión de datos (Align $\left.X^{\circledR}\right)$. Uno de los criterios principales de comparación y alineación fue la asignación de residuos estructuralmente equivalentes, con más de $70 \%$ de identidad.

Resultados. La organización estructural de la proteína E-ZIKV (PDB: 5iZ7) fue similar a la de E1-RV (PDB: 4ADG) (70 a $80 \%$ de identidad), y se observó una correspondencia con la estructura definida para las glucoproteínas de fusión de membrana de clase II de los virus con envoltura. E-ZIKV y E1RV exhibieron elementos estructurales de fusión muy conservados en la región distal del dominio II, asociados con la unión a los receptores celulares de entrada del virus de la rubéola (glucoproteína de mielina del oligodendrocito, Myelin Oligodendrocyte Glycoprotein, MOG), y con los receptores celulares AxI del ZIKV y de otros flavivirus.

Conclusión. La comparación de las proteínas E-ZIKV y E1-RV es un paso necesario hacia la definición de otros factores moleculares determinantes del neurotropismo y la patogenia del ZIKV, el cual puede contribuir a generar estrategias de diagnóstico, prevención y tratamiento de las complicaciones neurológicas inducidas por el ZIKV.

Palabras clave: virus Zika; virus de la rubéola; estructura molecular; microcefalia; glucoproteína de la mielina del oligodendrocito.

doi: http://dx.doi.org/10.7705/biomedica.v37i0.3807

E-ZIKV and E1-RV proteins molecular structure and their potential implications in neurotropism and nervous system disorders

Introduction: Zika virus (ZIKV) is an enveloped flavivirus transmitted to humans mainly by Aedes aegypti. ZIKV infection has been associated with high neurotropism and neuropathic effects such as the Guillain-Barré syndrome in adults, and fetal and postnatal microcephaly and the congenital Zika virus syndrome similar to that produced by rubella virus (VR).

Objective: To compare Zika virus membrane protein $\mathrm{E}$ (E-ZIKV) and rubella virus membrane protein E1 (E1-RV), and to propose possible implications for neurotropism and nervous system disorders associated with ZIKV infections.

\section{Contribución de los autores:}

Luis Alberto Gómez: concepción y formulación de la hipótesis, planteamiento del objetivo y la pregunta de investigación, obtención de las estructuras moleculares, interpretación y discusión de los resultados

Gladis Montoya: obtención de las estructuras moleculares

Todos los autores participaron en el análisis comparativo de resultados y la escritura del manuscrito. 
Materials and methods: The amino acid sequence of E-ZIKV protein (PDB: 5iZ7) was aligned to that of rubella virus glycoprotein E1 (PDB: 4ADG). The secondary structure elements were determined

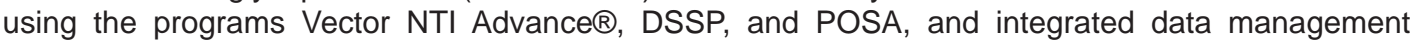
tools $($ AlignX®). One of the main comparison and alignment criteria was the allocation of structurally equivalent residues with more than $70 \%$ identity.

Results: E-ZIKV structural organization (PDB: 5iZ7) was similar to that of E1-RV (PDB: 4ADG) (70\%$80 \%$ identity), and it was consistent with relevant structural features of viral membrane class II fusion glycoproteins. E-ZIKV and E1-RV exhibited highly conserved fusion structural elements at the distal region of domain II, which has been associated with the RV myelin oligodendrocyte glycoprotein and AxI cell receptors in ZIKV and other flaviviruses.

Conclusion: The comparison of E-ZIKV and E1-RV proteins constitutes an essential step towards the definition of ZIKV neurotropism and pathogenesis molecular determinants, and for the adoption of diagnosis, prevention and treatment strategies against neurological complications induced by ZIKV infection.

Key words: Zika virus; rubella virus; molecular structure; microcephaly; oligodendrocyte-myelin glycoprotein.

doi: http://dx.doi.org/10.7705/biomedica.v37i0.3807

Una de las principales amenazas a la salud pública que emergieron en el 2016 en las Américas fue el brote de la infección por el virus del Zika (ZIKV), flavivirus de la familia Flaviviridae, transmitido a los seres humanos principalmente por el vector Aedes aegypti (1).

El reconocimiento de la asociación del ZIKV con una infección congénita grave, caracterizada por muertes fetales, microcefalia fetal y neonatal, calcificaciones, atrofia, dilatación ventricular, hipoplasia de estructuras cerebrales, lesiones retinianas y anomalías músculo-esqueléticas, así como con el síndrome de Guillain-Barré en el adulto (2-4), refuerza los indicios clínicos del neurotropismo del ZIKV y la relación directa de la infección con anomalías del sistema nervioso central en fetos y neonatos, y con el síndrome de Guillain-Barré en adultos (2-5).

La infección por el ZIKV en el sistema nervioso central del feto en desarrollo (2) sugiere un efecto neuropático directo asociado con la inducción de la muerte neuronal de células indiferenciadas progenitoras con capacidad de autorrenovación (5-8). Asimismo, la comprobación serológica de la infección por el ZIKV en pacientes con el síndrome de Guillain-Barré y los estudios de conducción nerviosa sugieren la presencia de una neuropatía

\footnotetext{
Correspondencia:

Luis Alberto Gómez, Grupo de Fisiología Molecular, Subdirección de Investigación Científica y Tecnológica, Dirección de Investigación en Salud Pública, Instituto Nacional de Salud, Avenida calle 26 N $^{\circ} 51-20$, Bogotá, D.C., Colombia Teléfono: (571) 220 7700, extensiones 1483, 1419 y 1416 lgomez@ins.gov.co

Recibido: 16/02/17; aceptado: 23/02/17
}

axonal aguda $(4,8,9)$. Aunque la detección del virus o su confirmación virológica se logra en menos del $50 \%$ de los pacientes afectados por el síndrome (10), el hallazgo de anticuerpos IgG anti-glucolípidos, especialmente los dirigidos a gangliósidos, así como los datos epidemiológicos, clínicos y experimentales, también sugieren un neurotropismo y una neurotoxicidad viral directa del ZIKV en el sistema nervioso periférico $(4,6,10)$; sin embargo, aún se desconocen los mecanismos celulares y moleculares del neurotropismo y la patogenia del virus, y de las alteraciones del sistema nervioso, incluidos la microcefalia y el síndrome de Guillain-Barré.

Al igual que otros flavivirus, como el virus del dengue (DENGV-1-4), el virus de la fiebre amarilla (YFV), el virus del Nilo occidental (WNV) y el virus de la encefalitis japonesa (JEV), entre otros $(1,11)$, el ZIKV es un virus con envoltura cuyo genoma es un ARN de cadena sencilla de orientación positiva, con un tamaño de aproximadamente 11.000 (11 kb) nucleótidos (11). La transcripción genera un polipéptido que se procesa en tres proteínas estructurales (de la cápside: C; de membrana: M, y de membrana envolvente: E) y siete proteínas no estructurales (NS1, NS2A, NS2B, NS3, NS4A, NS4B, NS5) (12). En general, los virus con envoltura se unen y entran a sus células huéspedes mediante la fusión con la membrana celular (13), utilizando un mecanismo de endocitosis y transporte por endosomas que depende en parte de la exposición a un $\mathrm{pH}$ bajo $(13,14)$ y se efectúa a través de las proteínas virales de fusión de membranas, las cuales son las principales implicadas en la unión al receptor, en la fusión y en la entrada a las células del huésped $(13,14)$. 
La estructura del ZIKV se describió recientemente con base en imágenes de criomicroscopía electrónica $(12,15)$, con las cuales fue posible detectar y caracterizar la estructura de la proteína de envoltura E del virus (ZIKV-E) unida a un anticuerpo específico (16).

Entre las características observadas en la estructura de la superficie de la partícula viral se cuentan 180 copias de la proteína $\mathrm{E}$ (proteína de envoltura), asociadas a la proteína M (proteína de membrana) $(14,15)$. La proteína $M$ es una proteína pequeña que se oculta bajo la capa de la proteína $\mathrm{E}$. Las proteínas $\mathrm{E}$ y $\mathrm{M}$ se organizan en una simetría de icosaedro que consta de 60 unidades repetidas, cada una de las cuales contiene tres proteínas E individuales (15). Las proteínas E se disponen como dímeros, con tres dímeros paralelos entre sí, los cuales forman una especie de balsa. Hay 30 de tales balsas que cubren la superficie viral. La mayor parte de la proteína E, que protruye de la bicapa lipídica, se conoce como el ectodominio E (15), que contiene tres dominios, DI, DII y DIII, conservados en otros flavivirus; las comparaciones estructurales de la proteína de la envoltura E-ZIKV revelan que algunas de sus regiones se asemejan mucho a las de los virus neurovirulentos como el WNV y el JEV, en tanto que otras son similares a las del virus del dengue (DENGV 1-4) (14). De todas maneras, aunque se sabe que la proteína $E$ contribuye al neurotropismo del ZIKV, los efectos en la fisiopatología aún no se han dilucidado.

Por otro lado, el virus de la rubéola (RV), de la familia Togaviridae, es un virus envuelto con ARN de cadena positiva que, al igual que el virus del Zika, también atraviesa la barrera placentaria cuando infecta a una mujer embarazada $(17,18)$. El principal problema de salud pública que plantea la rubéola también es su teratogenicidad, causante de muerte fetal y microcefalia, daños que son más graves cuando la infección materna se produce tempranamente en la gestación (18). El virus de la rubéola contiene tres polipéptidos estructurales principales, E1, E2 y C, y su superficie contiene las glucoproteínas E1 (E1-RV) y E2, según se ha podido determinar mediante métodos bioquímicos y de criomicroscopía electrónica $(19,20)$. La proteína E1-RV está implicada en el reconocimiento de la glucoproteína de mielina del oligodendrocito (MOG), receptor celular del virus de la rubéola que induce anticuerpos neutralizantes (21).

Dadas las características neurotrópicas de los virus del Zika y la rubéola, además de algunos aspectos de la biología molecular de su entrada a las células neuronales, así como por las consecuencias y las complicaciones de la infección congénita por el ZIKV y el RV, en el presente estudio se planteó como hipótesis la existencia de una similitud en la estructura molecular de las proteínas E-ZIKV y E1-RV.

El objetivo del estudio, entonces, fue comparar las estructuras moleculares de estas dos proteínas, así como describir algunas de las características comunes que pudieran constituir una explicación parcial del neurotropismo del ZIKV y de las alteraciones del sistema nervioso central y periférico que produce, como el síndrome congénito por el virus del Zika y el síndrome de Guillain-Barré, y discutir sus posibles implicaciones.

\section{Materiales y métodos}

El análisis de la secuencia de aminoácidos de las proteínas E-ZIKV (PDB: 5iZ7) y E1-RV (PDB: $4 A D G$ ), así como la identificación de los grupos de aminoácidos con estructura secundaria semejante, incluyó la composición de aminoácidos, la polaridad, la hidrofobicidad, la hidrofilicidad, los parámetros de conformación de las hojas beta, las hélices alfa, los bucles, las cisteínas y los puentes disulfuro (22). La alineación de las secuencias de las proteínas, la estadística y la edición de la alineación se obtuvieron usando las herramientas de análisis ofrecidas por el programa Vector NTI Advance ${ }^{\circledR}$ y el módulo de aplicación Align ${ }^{\circledR}$, empleado como herramienta de gestión de datos integrados para la visualización de las secuencias alineadas obtenidas con el programa Clustal-W $(23,24)$.

Para la asignación y definición de los elementos de la estructura secundaria, se utilizaron los programas Definition of Secondary Structure of Proteins (DSSP) (25) y Homology Derived Secondary Structure of Proteins (HSSP) (26) a partir de las secuencias de la proteína E1 del virus de la rubéola (PDB: 4ADG) y E del virus del Zika (PDB: 5iZ7). La superposición de las estructuras en tres dimensiones de las proteínas E-ZIKV (PDB: 5iZ7) y E1-RV (PDB: 4ADG) se hizo con el programa Partial Order Structure Alignment (POSA, http://posa.godziklab.org), alineando los primeros 200 residuos de cada proteína (25). El principal criterio para la determinación de algunas características y elementos comunes de las estructuras primaria y secundaria de la conformación tridimensional asignada, así como de la alineación de las estructuras, consistió en que los dominios y las regiones mostraran más de $70 \%$ de identidad entre sí (26). 


\section{Resultados}

Mediante el análisis de las secuencias de aminoácidos de las proteínas E y E1 de los virus del Zika y de la rubéola (E-ZIKV y E1-RV, respectivamente), se evidenció que el porcentaje de similitud en las secuencias de los 547 aminoácidos de la proteína E-ZIKV y los 481 aminoácidos de la proteína E1REV alineados por identidad $(n=69)$ y carga $(n=46)$, fue de $45 \%$ (figura 1). El punto isoeléctrico de la proteína E fue de 6,65 y, el de la E1, de 6,50.

Aunque la conservación de la composición y la secuencia de los aminoácidos (estructura primaria) fue relativamente moderada en las dos proteínas, la comparación y la alineación de los elementos estructurales (estructura secundaria) de la proteína E-ZIKV mostraron una mayor homología (entre 70 y $80 \%, 1.028$ residuos y 40 elementos estructurales identificados), que la ya conocida en la proteína E1-
RV (25). La proteína E-ZIKV presentó tres dominios estructurales (DI, DII y DIII) localizados en la parte externa de la membrana, los cuales contenían, esencialmente, 25 hojas beta que también se encontraron en la E1-RV (figuras $2 \mathrm{~A}$ y B, y 3 ). Otra característica estructural similar a las de la E1RV fue la presencia de tres dominios: un dominio central, o dominio I, con un núcleo plegado como un barril de ocho hojas beta de orientación antiparalela, con topología ascendente y descendente, desde $\mathrm{B}_{0}$ hasta $I_{0}$ (en rojo en las figuras 2 y 3 ). En el dominio II (en amarillo en las figuras), se observaron dos digresiones o prolongaciones largas que conectaban las cadenas adyacentes al núcleo central o dominio I: una entre las hojas beta $D_{0}$ y $E_{0}$, y la otra, entre las hojas beta $\mathrm{H}_{0}$ e I (figuras $2 \mathrm{~B}$ y 3 ). En la primera digresión se localizó un bucle de fusión en la conexión de las hojas beta $\mathrm{D}_{0} \mathrm{E}_{0}$ de la proteína E-ZIKV, equivalente al de la E1-RV (figura 2B).

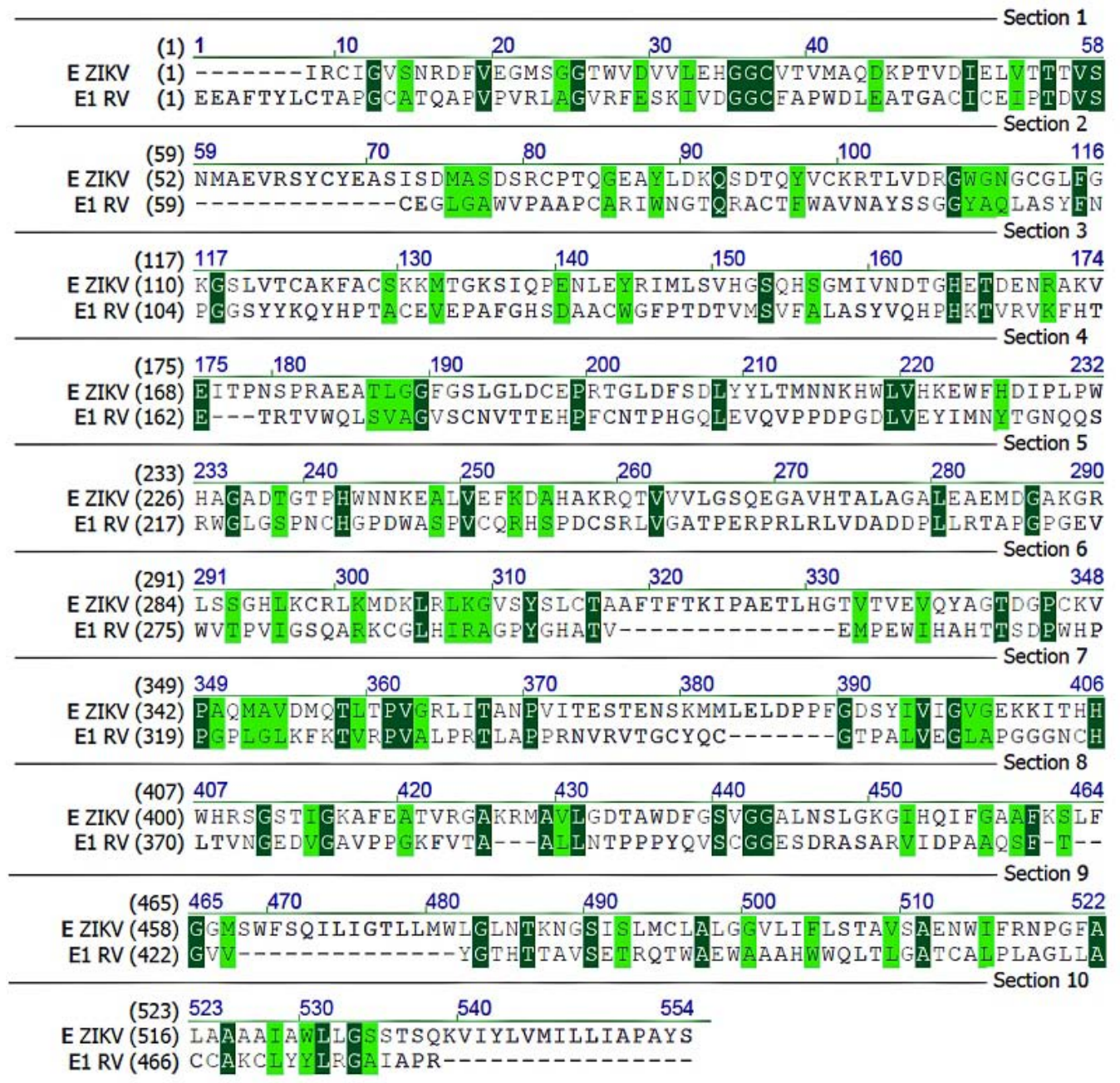

Figura 1. Estructura primaria y alineación de las secuencias de aminoácidos de la proteína E-ZIKV (entrada PDB 5IZ7) y de la proteína E1-RV (entrada PDB 4ADG) alineadas por identidad (color verde oscuro) y carga (color verde claro) de aminoácidos 
A.

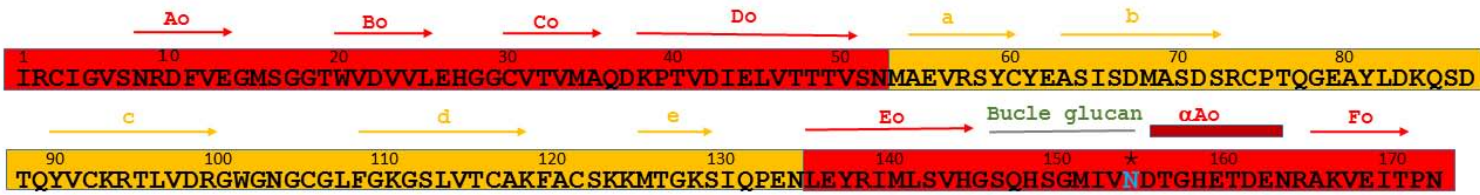

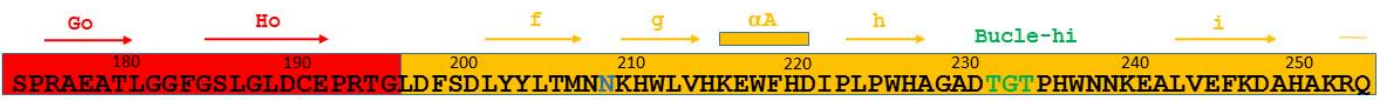
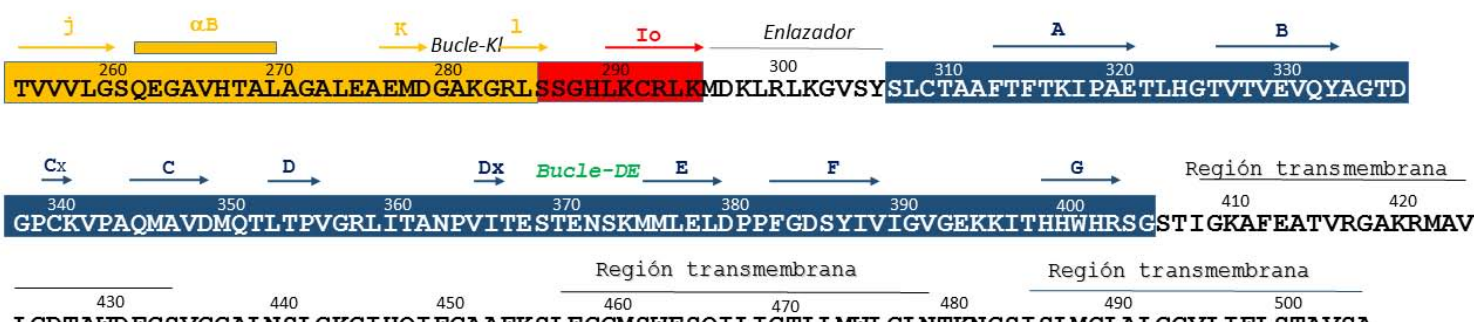

LGDTAWDFGSVGGALNSLGKGIHQIFGAAFKSLF GGMSWF SQILIGTLLMWLGLNTKNGSISLMCLALGGVLIFLSTAVSA

ENWI FRNPGFALAAAAIAWLLGSST SQKVIYLVMILLIAPAYS

B.

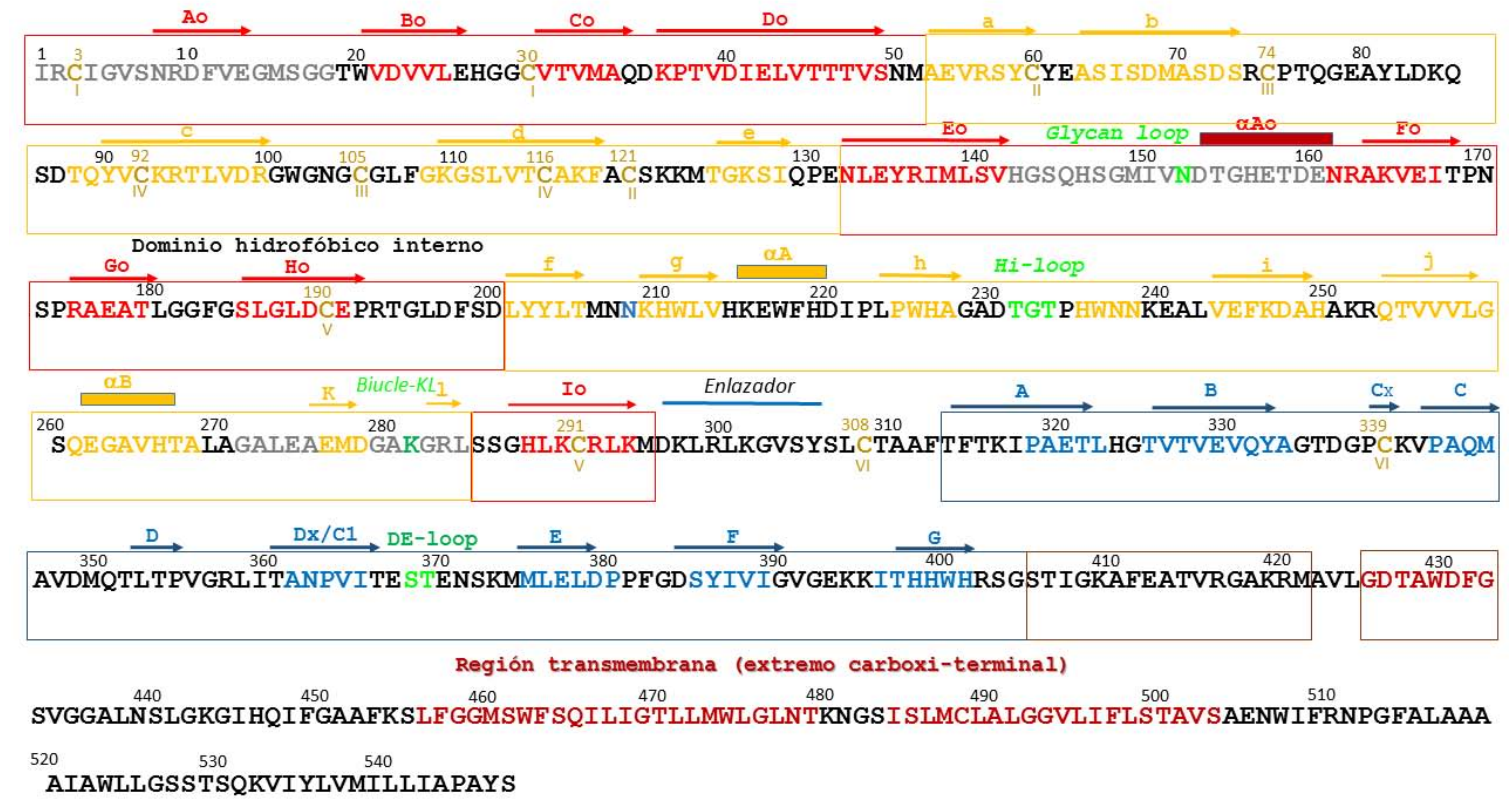

Figura 2. Localización de dominios, cisteínas y puentes disulfuro en la proteína E-ZIK. A. Las flechas de colores muestran la localización de los dominios estructurales I, II y III de E-ZIKV y E1-RV, los cuales contienen esencialmente varias hojas beta antiparalelas. El dominio central, o dominio I, tiene ocho hojas beta; el dominio II contiene diez y, el dominio III, siete. También se señalan las regiones amino-terminal, central y carboxi-terminal y las regiones transmembrana de las proteínas E-ZIKV y E1-RV. B. Ubicación de las cisteínas y representación esquemática de los puentes disulfuro identificados en las proteínas E-ZIKV y E1RV. Los residuos de cisteína se señalan por su posición (número en amarillo, parte superior de las cisteínas-C-) y los puentes disulfuro aparecen enumerados consecutivamente (números romanos de color amarillo en la parte inferior de las cisteínas-C-). Los potenciales puentes disulfuro de la E-ZIKV (entrada 5iZ7 de PDB) se alinearon por similitud estructural con los puentes disulfuro de la E1-RV (entrada 4ADG de PDB). En color verde se muestran, debajo de la punta del dominio II, las cisteínas 92 y 82 en las hojas beta C de las proteínas E-ZIKV y E1-RV, respectivamente, las cuales hacen parte del dominio hidrofóbico interno implicado directamente en eventos de fusión.

La estructura del dominio II de la E-ZIKV conservó las diez hojas beta (señaladas en la figura 3 con letras minúsculas de la a a la $i$, en tanto que los aminoácidos aparecen en amarillo). En este dominio, se diferenciaron dos regiones: una región proximal del dominio I, cuyo eje central estuvo configurado 
por las hojas beta "gfeah", y una región distal de dicho dominio con el bucle de fusión (FL) en la posición más alejada del dominio (figura 2). La región distal del dominio II contenía una estructura tridimensional de hojas beta "bdc", conservada en las dos proteínas E-ZIKV y E1-RV (figuras 3 y 4). Sin embargo, en la proteína E1-RV se observó contra la horquilla beta-ij un bucle "cd" que hacía parte del lazo de fusión (FL1) (figuras 3 y 4). El dominio III de E-ZIKV presentó las siete hojas beta, de la $A$ a la $G$ (figura 3, aminoácidos marcados en color azul), conservadas en E1-RV y se conectó al dominio I a través de una región enlazadora (linker) corriente abajo de la cadena $\mathrm{I}_{0}$ (figura 3 , aminoácidos marcados en color azul claro). La estructura del segmento entre los residuos 295 y 304 de ZIK-E1 (correspondientes al enlazador entre los dominios I y III), y del segmento entre los residuos 329 y 337 de RV-E1, fue similar (figura 3). Estos hallazgos sugieren que la predicción de la estructura molecular de la proteína E-ZIKV conservó las hojas beta estándar de las proteínas de fusión de clase II, de manera similar a como sucede en la estructura conocida de la glucoproteína E1 del virus de la rubéola.

Otros elementos comparados en la organización estructural de las dos proteínas fueron los enlaces disulfuro (figura 2B). La proteína E-ZIKV presentó 13 cisteínas que podían formar seis posibles puentes disulfuro entre las cisteínas $\mathrm{C}(3)$ y $\mathrm{C}(30)$, $C(60)$ y $C(121), C(74)$ y $C(105), C(92)$ y $C(116)$,

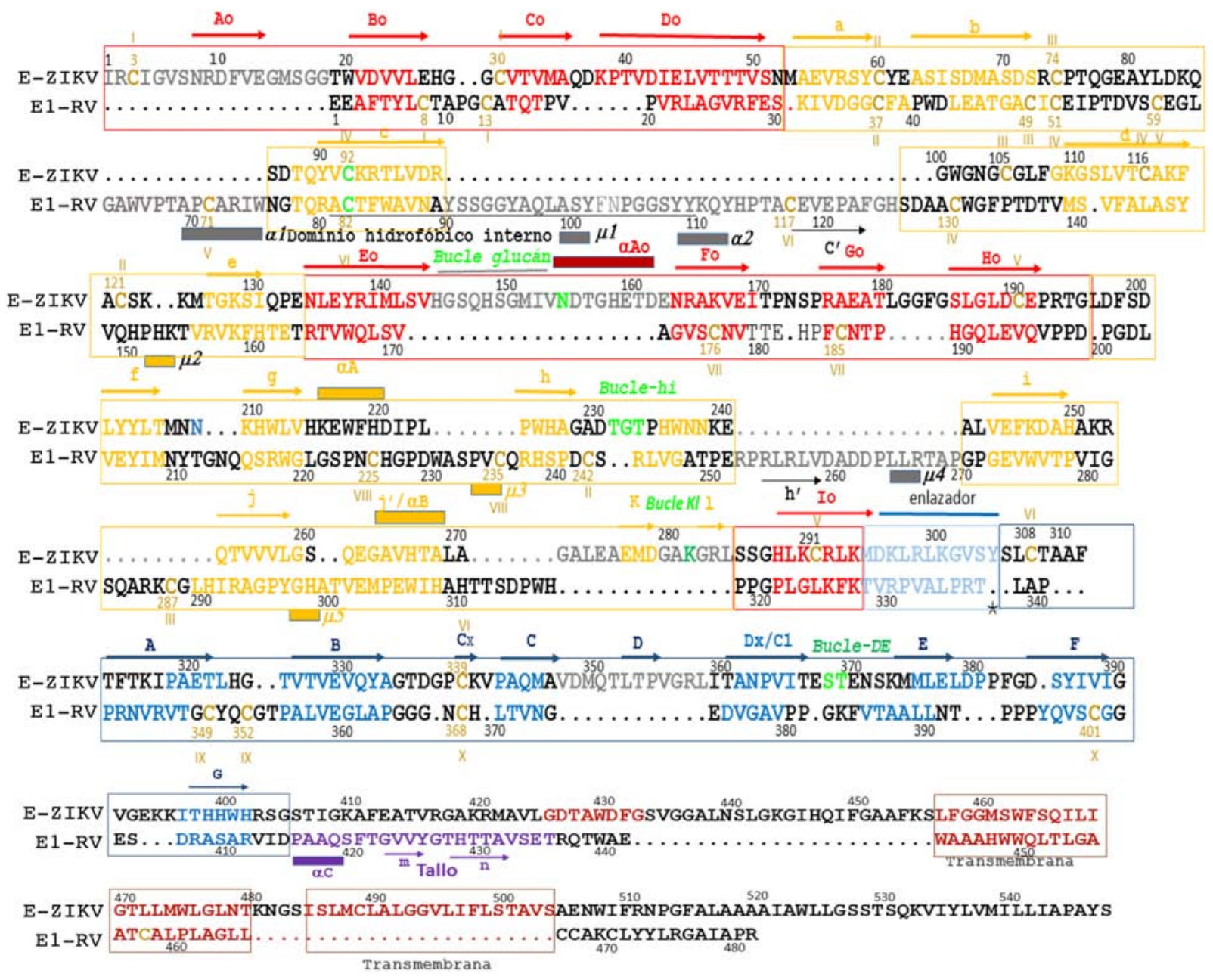

Figure 3. Comparación y alineación de los principales elementos de la estructura secundaria de la proteína E-ZIKV con los de la proteína E1-RV. El color de la caja indica los dominios correspondientes alineados por similitud estructural: en color rojo, el dominio I, en amarillo, el dominio II, y en azul oscuro, el dominio III. Las letras en color gris indican los aminoácidos que son específicos para las proteínas E-ZIKV y E1-RV. Los grupos de aminoácidos estructuralmente similares están en el color correspondiente (rojo, amarillo y azul). Los elementos de la estructura secundaria se determinaron como se describe en la sección de materiales y métodos, y la alineación estructural entre las dos proteínas se obtuvo mediante una comparación pareada de manera manual. 


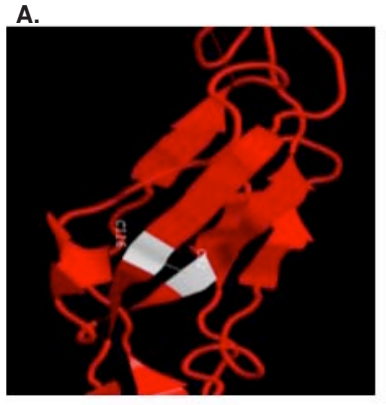

Proteína $\mathrm{E}$ del virus del Zika (E-ZIKV)
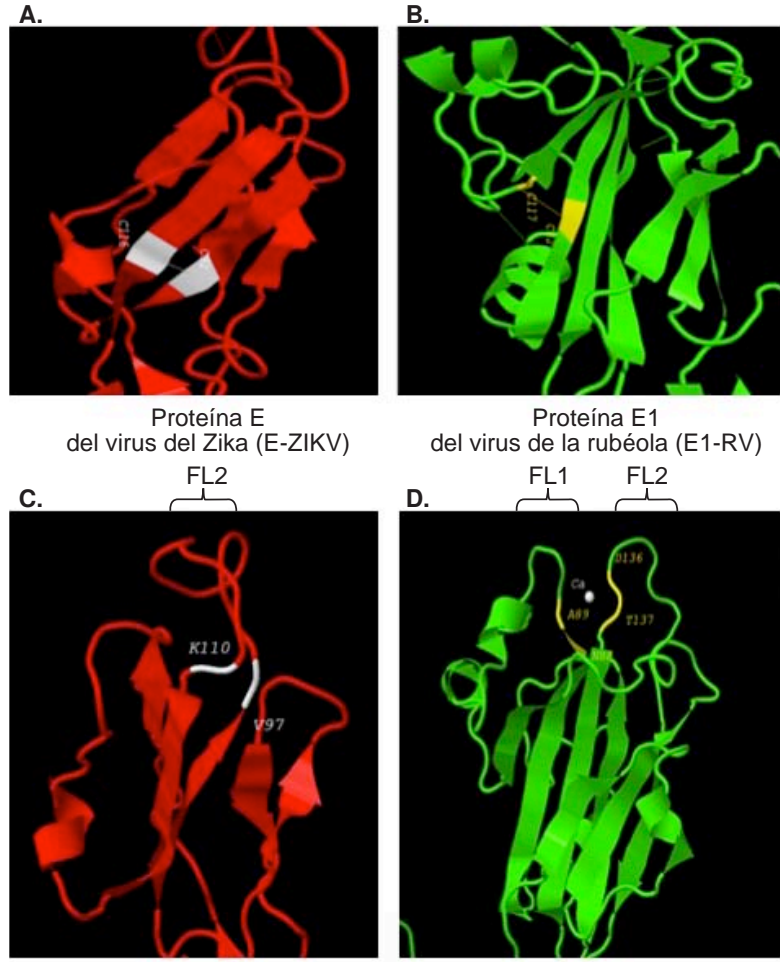

Proteína E1

del virus de la rubéola (E1-RV)

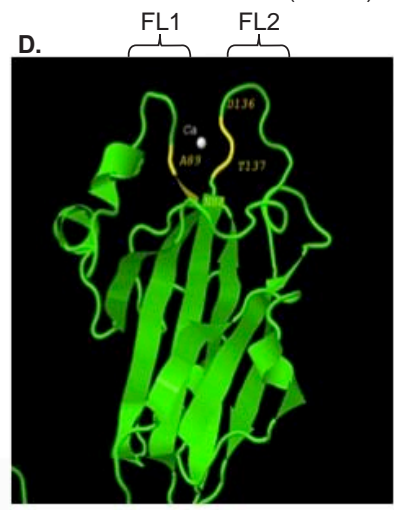

Figura 4. Estructura en 3D de la región distal del dominio II de las proteínas E-ZIKV y E1-RV. A. y B. Hojas beta, c y d, de la región distal de la proteína E-ZIKV (color rojo) y de la proteína E1-RV (color verde), respectivamente. En color blanco, se resalta la cisteína 92 en E-ZIKV y, en amarillo, la cisteína 82 de E1-RV. Se señalan los puentes disulfuro identificados utilizando el algoritmo RasMol del programa POSA. En blanco, se señalan los puentes disulfuro entre la Cys 92 y la Cys 117 de la proteína E-ZIKV, y en amarillo, entre la Cys 82 y la Cys 117, los de la proteína $\mathrm{E} 1-\mathrm{RV}$, los cuales se organizan y acercan las hojas beta, c y d, en el dominio II. C.y D. Acercamiento a la región de los bucles de fusión FL1 y FL2, localizados en la punta del dominio II de las proteínas E-ZIKV y E1-RV. En color rojo, se identifica el bucle FL2 de E-ZIKV (C.) y, en color verde, los bucles FL1 y FL2 de E1-RV. En color blanco, aparece el bucle FL2 en la proteína E1-ZIKV, homólogo putativo del bucle FL2 de E1-RV, el cual se definió desde el residuo Val 97 hasta el residuo Lys 110. En D. se detalla el sitio ocupado por el ión de calcio y los aminoácidos que participan en el sitio de unión (32). Con un punto central en blanco, se representa el calcio entre los bucles FL1 y FL2, localizado entre los residuos Asn 88 y Asp 136 (en color amarillo) de los bucles FL1 y FL2, respectivamente.

C(190) y C(291), C(308) y C(33) (figura 2B). Por su parte, en la proteína E1-RV se observaron 24 cisteínas que formaron diez puentes disulfuro entre las cisteínas $\mathrm{C}(8)$ y $\mathrm{C}(13), \mathrm{C}(37)$ y $\mathrm{C}(242), \mathrm{C}(49)$ y $C(287), C(51)$ y $C(130), C(59)$ y $C(71), C(82)$ y $\mathrm{C}(117), \mathrm{C}(176)$ y $\mathrm{C}(185), \mathrm{C}(225)$ y $\mathrm{C}(235), \mathrm{C}(349)$ y C(352), C(368) y C(401) (figura 2B). También, se observó la conservación de algunas cisteínas, en especial de la cisteína 92 en la proteína E-ZIKV y de la cisteína 82 en la proteína E1-RV, que

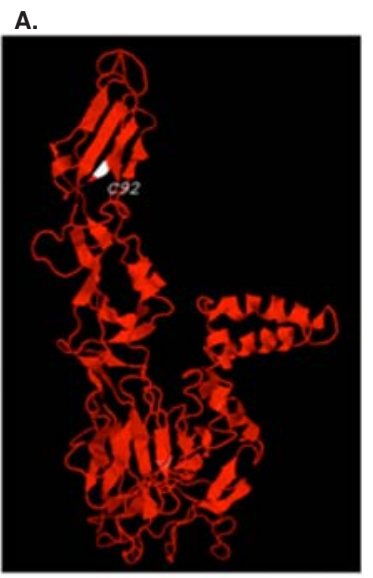

Proteína $\mathrm{E}$

del virus del Zika (E-ZIKV)

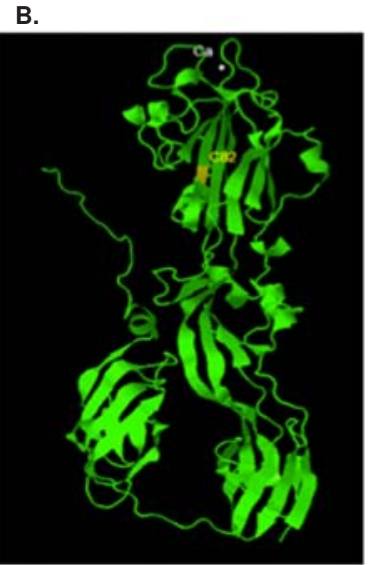

C.

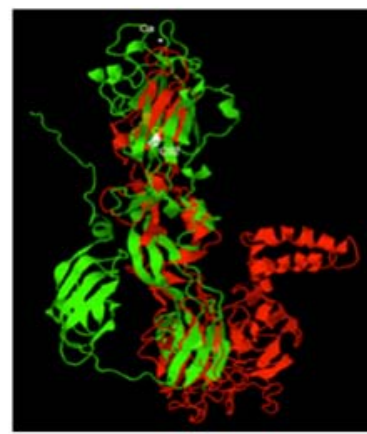

Alineamiento estructural de las proteínas E-ZIKV y E1-RV

del virus de la rubéola (E1-RV)

Figura 5. Estructura y alineamiento estructural en 3D de las proteínas virales E1 -ZIKV y E1-RV a partir de los primeros 200 aminoácidos que componen cada proteína usando el programa POSA. A. Estructura en 3D de la proteína E-ZIKV (en rojo). B. Estructura en 3D de la proteína E1-RV (en verde) C. Superposición de las estructuras en 3D de las proteínas E-ZIKV (en rojo) y E1-RV (en rojo)

formaron un puente disulfuro con las cisteínas 116 y 117, respectivamente, y que se localizaron entre las hojas beta, c y d, del bucle de fusión hidrofóbico interno conservado en el dominio II de ambas proteínas (figuras 3 y 4 A y B).

Por otra parte, la comparación de las estructuras de E-ZIKV y E1-RV mostró también algunas diferencias. Los dominios I y III de E-ZIKV eran más grandes, alrededor de 46 y 19 residuos, respectivamente (122 para E-ZIKV Vs. 80 para E1RV 80 en el dominio I; y 76 para E-ZIKV Vs. 61 para E1-RV en el dominio III). Asimismo, los residuos de las regiones transmembrana (cuatro para E-ZIKV y dos para R1-RV) abarcaron alrededor de 55 residuos para E-ZIKV y 25 para E1-RV (figura 3). 
Por el contrario, el dominio II de E-ZIKV era más pequeño que su contraparte en $\mathrm{E} 1-\mathrm{RV}$, y en él se observó una hélice alfa corta anfipática (a2) y una vuelta de hélice $\mu 1$ (figura 3). Flanqueando esta región de E1-RV, se localizaron los bucles1 y 2 (FL1 y FL2: residuos 88-93 y 131-137, respectivamente) (figura 4 A y B). El bucle FL1 no se observó en la proteína E-ZIKV (figuras 4 C y D), sin embargo, el bucle entre los residuos 100 y 108 de E-ZIKV era similar al FL2 (figuras 3,4 y 5). También, se observó un sitio de glucosilación (NGS) en el aminoácido Asn (N) 154 de la proteína E-ZIKV, en tanto que en la proteína E1-RV se observaron tres de dichos sitios: uno en el aminoácido $\mathrm{N}$ 209 y los otros dos en el dominio II (N76) y en el dominio I (N177), así como residuos para $\mathrm{N}$-acetil glucosamina (NAG) en los residuos T429 y T430 en la proteína E1-RV, los cuales no se observaron en la proteína E-ZIKV (figura 3, tallo). Se ha sugerido que el sitio de glucosilación N154 de E-ZIKV, el cual también se encuentra en otros flavivirus, es un factor determinante de la neurovirulencia del WNV, pero no en los virus del dengue que conservan este sitio de glucosilación (27).

A diferencia de la proteína E1-RV, la E-ZIKV presentó las siguientes inserciones: un bucle glucano entre los residuos 144 a 153 y una hélice aAo entre los residuos 154 a 161, y entre las hojas beta, Eo y Fo, en el dominio I, que también se conserva en los virus WNV y JEV (no se presentan los datos)(12). Otras inserciones de E-ZIKV comparadas con la E1RV fueron el $\mathrm{Hi}$-loop entre los residuos 230 y 234 y el bucle KI entre los residuos 271 a 284 del dominio II (figuras 2 y 3 , aminoácidos marcados en color verde), los cuales se conservan en los virus WNV, TBE y YFV (no se presentan los datos). Además, E-ZIKV presentó el bucle CD entre los residuos 346 y 351 y el bucle Dx/D1 entre los residuos 352 y 359 en el dominio III, los cuales se han asociado con una superficie más compacta del virus (figura 5), que le conferiría más estabilidad y más resistencia a la temperatura, comparadas con las de otros virus con envoltura, y podría explicar, en parte, la presencia del ZIKV en diferentes fluidos, incluidos la orina, la saliva, el semen y el líquido cefalorraquídeo, entre otros (12).

\section{Discusión}

El virus del Zika afecta el sistema nervioso y puede generar malformaciones en el feto, y el síndrome de Guillain-Barré en el adulto $(28,29)$. Un efecto directo del ZIKV en las células del sistema nervioso implicaría mecanismos moleculares neurotrópicos y de entrada mediados por receptores (29). La mayoría de los virus con envoltura de membrana, como el ZIKV, entran en las células a través de las proteínas de fusión de la membrana viral y de las membranas celulares transportadas por endosomas celulares (13). Existen tres clases de proteínas de fusión de membranas virales clasificadas con base en criterios estructurales y mecanismos que desencadenan la fusión (13). Las proteínas de fusión de clase II están ancladas en la bicapa lipídica de la membrana a través de su dominio transmembrana, y están compuestas principalmente por hojas beta, con uno o dos bucles de fusión en la punta del dominio II, y por un dominio de hoja beta extendido (14).

La similitud de la estructura molecular de las proteínas E-ZIKV y E1-RV (figuras 3-5), determinada por el alto contenido de hojas beta, la conservación de algunas cisteínas y de algunos puentes disulfuro, en especial el puente disulfuro entre las hojas beta, c y d, en el bucle hidrofóbico interno de fusión del dominio 2 (figuras 2-4), así como un posible patrón de glucosilación similar en los aminoácidos N-154 en E-ZIKV y N-209 en E1-RV, la ausencia del sitio de glucosilación en el aminoácido N-67 de E-ZIKV y su homólogo en E1-RV, y su reemplazo por dos aminoácidos de polaridad y carga similar, el D-67 en ZIKV-E y el E-44en RV-E1 (30-32), sugieren que la proteína E-ZIKV es una glucoproteína de envoltura de fusión de clase II, y que tanto E-ZIKV como E1-RV pueden tener propiedades bioquímicas y funcionales similares en cuanto a la fusión y la entrada de estos virus mediada por receptores celulares específicos.

Se ha descrito que los bucles FL1 Y FL2 de E1$\mathrm{RV}$ se unen a átomos de calcio, unión que se ha asociado con un mecanismo de fusión a la célula huésped mediada por calcio en el RV (32). La estructura del FL1 de E1-RV se da por una inserción de aminoácidos que no se encuentra en la E1-ZIKV (figuras 3-5). No obstante, en la E-ZIKV el bucle similar al FL2, y el dominio hidrofóbico interno (cd) compartido por las dos proteínas podrían contribuir con una superficie de fusión a las membranas de las células huéspedes como se ha propuesto para E1-RV (32).

Por otra parte, el bucle glucano entre los residuos 144 a 153 y la hélice $\alpha$ Ao entre los residuos 154 y 161 en el dominio I de la proteína E-ZIKV, también se conservan en los virus neuropáticos WNV y JEV $(12,33)$; asimismo, el bucle $\mathrm{Kl}$ entre los residuos 271 y 284 del dominio II (figuras 2 y 3), también 
se conserva en los virus WNV, TBE y YFV. El bucle CD entre los residuos 346 y 351 y el $D x /$ D1 entre los residuos 352 y 359 en el dominio III de E-ZIKV se han asociado con una superficie más compacta, más estable y más resistente a la temperatura $(12,15)$, comparada con la de otros virus con envoltura, lo cual explicaría, en parte, la viremia prolongada, su presencia en diferentes fluidos como la orina, la saliva, el semen y el líquido cefalorraquídeo, entre otros (34-36).

Estas y otras comparaciones de las proteínas de fusión de membrana en alfavirus y algunos flavivirus, incluidos los DENV 1 a 4, el YFV y el WNV, todos con elementos estructurales de fusión muy conservados, revelan una posible selección evolutiva y funcional de este tipo de proteínas $(32,36,37)$.

Los virus con envoltura, que contienen fosfatidilserina en sus membranas, pueden interactuar con receptores TAM, entre ellos, los miembros de las familias Tyro3, Axl y Mertk (38-40). Con base en los resultados de estudios en cultivos celulares, Nowakowski, et al. (41), han sugerido que los virus ZIKV, DENV y WNV pueden requerir receptores TAM para su fijación o entrada, y que la Axl actuaría como proteína de unión y receptor de entrada. La caracterización de la expresión de Axl en células madre neuronales fue el primer paso en la identificación de uno de los candidatos a ser el receptor de entrada del ZIKV (41). Se ha detectado este receptor $\mathrm{Axl}$, con actividad tirosina cinasa, en la señalización mediada por los receptores TLR (toll like receptors), y resulta pertinente anotar que la vía de señalización TLR3 se ha asociado con el daño celular inducido por el ZIKV, lo cual sugiere una relación entre el receptor $A x l$ y la patogenia del Zika (42).

Aunque la caracterización de la expresión de $A x I$ en las células del sistema nervioso central puede explicar la entrada del ZIKV, es necesario adelantar más estudios para confirmar si dicho receptor determina el tropismo celular del virus en células neuronales cultivadas y en vivo, así como su capacidad para infectar fibroblastos de piel (43) y células epiteliales de cordón umbilical (44). Debe señalarse, además, que todavía no se han determinado completamente los receptores celulares del ZIKV.

La similitud del bucle hidrofóbico interno de fusión de los virus neurotóxicos, como el WNV, el RV y el ZIKV, entre otros, sugiere que la entrada de estos virus neuropáticos ocurre mediante receptores y vías semejantes. Las evidencias de que el virus neurotóxico WNV puede adherirse a células con deficiencia de los receptores TAM (45), y que ratones genéticamente carentes de las proteínas Axl y Mertk exhibieron una mayor infección por el WNV en células de cerebro (38), sugieren que Axl y Mertk no serían receptores exclusivos de entrada de los virus neurotóxicos, por lo cual debería investigarse si esto también sucede con el ZIKV o si utiliza otro tipo de receptores.

La similitud de la estructura molecular de las proteínas E-ZIKV y E1-RV permite proponer otra posible explicación del neurotropismo del virus Zika, el cual se daría a través del bucle hidrofóbico interno y el bucle cd, ambos conservados en estas proteínas. La entrada del ZIKV a las células huésped mediada por otro tipo de receptores concuerda con las semejanzas estructurales halladas entre las proteínas E-ZIKV y E1-RV, en especial, la similitud del bucle hidrofóbico interno de fusión, sobre todo en la conservación de las cisteínas 92 y 82, las cuales forman un puente disulfuro que permitiría una organización estructural similar entre las hojas beta (cd) del dominio II y la posibilidad de que el virus Zika pueda ingresar a las células huésped a través de otro tipo de receptores celulares, como la MOG, al igual que sucede con el virus de la rubéola (21).

Esta hipótesis concordaría con la evidencia de que el cambio de la cisteína 82 por la alanina en la proteína E1-RV eliminó la capacidad de infección del virus (21), así como con el reciente hallazgo de que anticuerpos neutralizantes que reconocen un epítopo en el bucle de fusión de la proteína E-ZIKV, proporcionan protección contra la infección por el ZIKV en vivo e in vitro (16). Por lo tanto, es necesario evaluar experimentalmente si la cisteína 92 y la organización estructural entre las hojas beta (cd) del dominio II de la E-ZIKV también se requieren en el proceso de infección del ZIKV en las células neuronales mediado por este tipo de receptores.

La confirmación de la participación de diferentes receptores celulares de entrada del ZIKV proporcionaría una explicación plausible del neurotropismo diferencial y las alteraciones del sistema nervioso durante el desarrollo embrionario y en el adulto. Dicho neurotropismo diferencial durante el desarrollo se ha observado en estudios recientes en ratones, los cuales evidenciaron altos grados de infección por el ZIKV en el cerebro, la médula espinal $(6,46)$ y las células epiteliales $(44,46)$.

Aunque no se sabe por qué algunas células epiteliales y neuronales son más propensas a la infección por el ZIKV que otras (por ejemplo, las 
neuronas progenitoras lo son más que las corticales maduras) $(5,8,47)$, se podrían presentar diferentes mecanismos de entrada mediados por distintos tipos de receptores (por ejemplo, Axl o TAR), así como tasas de infección diferentes debido a cambios en el grado de expresión de factores del huésped requeridos para la entrada (por ejemplo, TLR3), la replicación o el ensamblaje del ZIKV (42). Además, las diferencias específicas del tipo celular en los programas de defensa intrínseca de las células también podrían explicar la variación en la infección por el ZIKV en distintos tipos de células epiteliales y neurales $(47,48)$.

En este momento, no es posible explicar con claridad las anormalidades neurológicas y el síndrome de Guillain-Barré como efecto directo del virus; además, en el caso del síndrome, no es posible descartar una reacción cruzada entre algunos flavivirus, como el virus del dengue, y la ausencia de anticuerpos antiglucolípidos en pacientes en quienes dicho síndrome se manifestó tempranamente $(4,49,50)$. Las diferencias observadas en los efectos de la infección por el ZIKV en el adulto y en el individuo en desarrollo sugieren que pueden existir diferentes factores que determinan el neurotropismo y la neurotoxicidad. Los datos disponibles sustentan la hipótesis de que el ZIKV podría generar una neurotoxicidad viral directa, tanto en el sistema nervioso central como en el periférico. El gran neurotropismo del ZIKV puede explicarse, no solo por la entrada y la señalización a través del receptor Axl, sino también, por un mecanismo de entrada mediado por la proteína E del ZIKV y un receptor celular como la MOG, de forma similar a lo observado con la proteína E1 del virus de la rubéola (21).

El desarrollo del fenotipo microcefálico y el síndrome de Zika congénito en el individuo en desarrollo, se explicaría por la participación de los receptores AxI en la infección por el ZIKV, lo cual induciría la muerte de progenitores neuronales $(5,8)$. Esto concuerda con el hallazgo de que diversos tipos celulares en el cerebro adulto, incluidos los astrocitos, pueden estar infectados con el ZIKV y, sin embargo, sobrevivir durante largos períodos (47). En modelos de la infección por el ZIKV en ratones, las neuronas mantuvieron una morfología normal a pesar de estar infectadas por el virus, y sobrevivieron durante un período prolongado $(6,46)$. Por otra parte, el mecanismo de desarrollo del fenotipo neuropático del adulto, es decir, el síndrome agudo de Guillain-Barré, sería diferente. La polineurorradiculopatía desmielinizante en el adulto, asociada a la infección por el ZIKV, podría explicarse por el potencial tropismo de la proteína E-ZIKV hacia la glucoproteína MOG, un marcador para oligodendrocitos diferenciados "maduros" que se expresa de manera tardía en el desarrollo y aparece en oligodendrocitos de la médula espinal y en el tronco encefálico en la etapa posnatal, y se considera un autoantígeno en procesos de desmielinización primaria $(51,52)$.

Considerando que en este trabajo se utilizó el prototipo de proteína E del virus ZIKV (entrada PDB 5I6Z7), y dada la existencia de diferentes aislamientos del ZIKV procedentes de Latinoamérica y Asia, es importante profundizar en las mutaciones 0 variantes de la secuencia y la estructura molecular del E-ZIKV que modifiquen el dominio hidrofóbico interno, el bucle de fusión u otros elementos estructurales que pueden sufrir modificación posterior a la traducción, incluidos los sitios de glucosilación (53), con lo cual se produciría un efecto en la capacidad de infección del ZIKV a otros tipos de células específicas $(2,54,55)$.

Además, en un futuro también sería importante determinar, experimentalmente y en especímenes clínicos, si la infección por el ZIKV de las células neuronales progenitoras $u$ otros tipos de células del sistema nervioso está mediada por la proteína E-ZIKV, si hay un neurotropismo diferencial en distintas fases del desarrollo y si la entrada del ZIKV a través de los receptores MOG y AxI puede explicar directamente la aparición del síndrome agudo de Guillain-Barré en el adulto, y la microcefalia y las anormalidades en el cerebro en desarrollo.

En conclusión, la comparación de las proteínas E-ZIKV y E1-RV, y la similitud hallada entre ellas, son un paso necesario para la definición de otros factores moleculares determinantes del neurotropismo y la patogenia del ZIKV, así como para generar estrategias de diagnóstico, prevención y tratamiento de las complicaciones neurológicas inducidas por el ZIKV.

\section{Agradecimientos}

Los autores agradecen al Instituto Nacional de Salud. Hernán Mauricio Rivera agradece a Colciencias por el apoyo como becario de doctorado.

\section{Conflicto de intereses}

Los autores declaran no tener conflicto de intereses.

\section{Financiación}

Esta investigación fue financiada con recursos del Instituto Nacional de Salud. 


\section{Referencias}

1. Fauci AS, Morens DM. Zika Virus in the Americas-yet another arbovirus threat. N Engl J Med. 2016;374:601-4. http://dx.doi.org/10.1056/NEJMp1600297

2. Mlakar J, Korva M, Tul N, Popović M, Poljšak-Prijatelj $\mathbf{M}$, Mraz J, et al. Zika virus associated with microcephaly. N Engl J Med. 2016;374:951-8. http://dx.doi.org/10.1056/ NEJMoa1600651

3. Rasmussen SA, Jamieson DJ, Honein MA, Petersen LR. Zika virus and birth defects-Reviewing the evidence for causality. N Engl J Med. 2016;374:1981-7. http://dx.doi. org/10.1056/NEJMsr1604338

4. Parra B, Lizarazo J, Jiménez-Arango JA, Zea-Vera AF, González-Manrique G, Vargas J, et al. Guillain-Barré syndrome associated with Zika virus infection in Colombia. N Engl J Med. 2016;375:1513-23. http://dx.doi.org/10.1056/ NEJMoa1605564

5. Li H, Saucedo-Cuevas L, Regla-Nava JA, Chai G, Sheets $\mathbf{N}$, Tang $\mathbf{W}$, et al. Zika virus infects neural progenitors in the adult mouse brain and alters proliferation. Cell Stem Cell. 2016;19:593-8. http://dx.doi.org/10.1016/j.stem.2016. 08.005

6. Lazear HM, Govero J, Smith AM, Platt DJ, Fernández E, Miner JJ, et al. A mouse model of zika virus pathogenesis. Cell Host Microbe. 2016;19:720-30. http://dx.doi.org/10. 1016/j.chom.2016.03.010

7. Garcez PP, Loiola EC, Madeiro da Costa R, Higa LM, Trindade P, Delvecchio R, et al. Zika virus impairs growth in human neurospheres and brain organoids. Science. 2016;352:816-8. http://dx.doi.org/10.1126/science.aaf6116

8. Mécharles S, Herrmann C, Poullain P, Tran TH, Deschamps N, Mathon G, et al. Acute myelitis due to Zika virus infection. Lancet. 2016;387:1481. http://dx.doi.org/10. 1016/S0140-6736(16)00644-9

9. Stettler K, Beltramello M, Espinosa DA, Graham V, Cassotta A, Bianchi S, et al. Specificity, cross-reactivity, and function of antibodies elicited by Zika virus infection. Science. 2016;353:823-6. http://dx.doi.org/10.1126/science. aaf8505

10. Lucchese G, Kanduc D. Zika virus and autoimmunity: From microcephaly to Guillain-Barré syndrome, and beyond. Autoimmun Rev. 2016;15:801-8. http://dx.doi.org/10.1016/j. autrev.2016.03.020

11. Petersen LR, Jamieson DJ, Powers AM, Honein MA. Zika virus.N Engl J Med. 2016;374:1552-63. http://dx.doi. org/10.1056/NEJMra1602113

12. Kostyuchenko VA, Lim EX, Zhang S, Fibriansah G, Ng TS, Ooi JS, et al. Structure of the thermally stable Zika virus. Nature. 2016;533:425-8. http://dx.doi.org/10.1038/ nature17994

13. White JM, Whittaker GR. Fusion of enveloped viruses in endosomes. Traffic. 2016;17:593-14. http://dx.doi.org/10. 1111/tra.12389

14. Kielian M. Mechanisms of virus membrane fusion proteins. Ann Rev Virol. 2014;1:171-89. http://dx.doi.org/10.1146/ annurev-virology-031413-085521.

15. Sirohi D, Chen Z, Sun L, Klose T, Pierson TC, Rossmann MG, et al. The $3.8 \AA$ resolution cryo-EM structure of Zika virus. Science. 2016;352:467-70. http://dx.doi.org/10.1126/ science.aaf5316
16. Dai L, Song J, Lu X, Deng YQ, Musyoki AM, Cheng H, et al. Structures of the Zika virus envelope protein and its complex with a flavivirus broadly protective antibody. Cell Host Microbe. 2016;19:696-704. http://dx.doi.org/10.1016/j. chom.2016.04.013

17. Cooper LZ, Krugman S. Clinical manifestations of postnatal and congenital rubella. Arch Ophthalmol. 1967;77:434-9. http://dx.doi.org/10.1001/archopht.1967.00980020436004

18. Lee JY, Bowden DS. Rubella virus replication and links to teratogenicity. Clin Microbiol Rev. 2000;13:571-87. http:// dx.doi.org/10.1128/CMR.13.4.571-587.2000

19. Waxham MN, Wolinsky JS. A model of the structural organization of rubella virions. Rev Infect Dis. 1985;7:S133-9.

20. Battisti AJ, Yoder JD, Plevka P, Winkler DC, Prasad VM, Kuhn RJ, et al. Cryo-electron tomography of rubella virus. J Virol. 2012;86:11078-85. http://dx.doi.org/10.1128/ JVI.01390-12

21. Cong H, Jiang Y, Tien P. Identification of the myelin oligodendrocyte glycoprotein as a cellular receptor for rubella virus. J Virol. 2011;85:11038-47. http://dx.doi.org/10. 1128/JVI.05398-11

22. Bairoch A, Apweiler R. The SWISS-PROT protein sequence data bank and its supplement TrEMBL. Nucleic Acids Res. 1997;25:31-6.

23. Thompson JD, Higgins DG, Gibson TJ. CLUSTAL W: Improving the sensitivity of progressive multiple sequence alignment through sequence weighting, position-specific gap penalties and weight matrix choice. Nucleic Acids Res. 1994;22:4673-80.

24. Sussman JL, Lin D, Jiang J, Manning NO, Prilusky $\mathrm{J}$, Ritter $\mathbf{O}$, et al. Protein Data Bank (PDB): Database of three-dimensional structural information of biological macromolecules. Acta Crystallogr D Biol Crystallogr. 1998:54:1078-84.

25. Kabsch W, Sander C. Dictionary of protein secondary structure: Pattern recognition of hydrogen-bonded and geometrical features. Biopolymers. 1983;22:2577-637. http://dx. doi.org/10.1002/bip.360221211

26. Sander C, Schneider R. Database of homology-derived protein structures and the structural meaning of sequence alignment. Proteins. 1991;9:56-68. http://dx.doi.org/10.1002/ prot.340090107

27. Ceccaldi PE, Lucas M, Despres P. New insights on the neuropathogenicity of West Nile virus. FEMS Microbiol Lett. 2004;233:1-6. http://dx.doi.org/10.1016/j.femsle.2004. 01.035

28. Araujo AQ, Silva MT, Araujo AP. Zika virus-associated neurological disorders: A review. Brain. 2016;139:2122-30. http://dx.doi.org/10.1093/brain/aww158

29. Miner JJ, Daniels BP, Shrestha B, Proenca-Modena JL, Lew ED, Lazear HM, et al. The TAM receptor Mertk protects against neuroinvasive viral infection by maintaining bloodbrain barrier integrity. Nat Med. 2015;21:1464-72. http://dx. doi.org/10.1038/nm.3974

30. Vidgren G, Takkinen $\mathbf{K}$, Kalkkinen N, Kääriäinen $\mathbf{L}$, Pettersson RF. Nucleotide sequence of the genes coding for the membrane glycoproteins E1 and E2 of rubella virus. J Gen Virol. 1987;68:2347-57. http://dx.doi.org/10.1099/00221317-68-9-2347 
31. Gros C, Linder M, Wengler G, Wengler G. Analyses of disulfides present in the rubella virus E1 glycoprotein. Virology. 1997;230:179-86. http://dx.doi.org/ 10.1006/viro. 1997.8462

32. DuBois RM, Vaney MC, Tortorici MA, Kurdi RA, BarbaSpaeth G, Krey T et al. Functional and evolutionary insight from the crystal structure of rubella virus protein E1. Nature. 2013;493:552-6. http://dx.doi.org/10.1038/nature11741

33. Beasley DW, Whiteman MC, Zhang S, Huang CY, Schneider BS, Smith DR. Envelope protein glycosylation status influences mouse neuroinvasion phenotype of genetic lineage 1 West Nile virus strains. J Virol. 2005;79:8339-47. http://dx.doi.org/10.1128/JVI.79.13.8339-8347.2005

34. Gourinat AC, O'Connor O, Calvez E, Goarant C, DupontRouzeyrol M. Detection of Zika virus in urine. Emerg Infect Dis. 2015;21:84-6. http://dx.doi.org/10.3201/eid2101. 140894

35. Musso D, Roche C, Nhan TX, Robin E, Teissier A, CaoLormeau VM. Detection of Zika virus in saliva. J ClinVirol. 2015;68:53-5. http://dx.doi.org/10.1016/j.jcv.2015.04.021

36. Burke RM, Pandya P, Nastouli E, Gothard P. Zika virus infection during pregnancy: What, where, and why? $\mathrm{Br}$ J Gen Pract. 2016;66:122-3. http://dx.doi.org/10.3399/ bjgp16X683917

37. Deng YQ, Zhao H, Li XF, Zhang NN, Liu ZY, Jiang T, et al. Isolation, identification and genomic characterization of the Asian lineage Zika virus imported to China. Sci China Life Sci. 2016;59:428-30. http://dx.doi.org/10.1007/s11427-0165043-4

38. Miner JJ, Daniels BP, Shrestha B, Proenca-Modena JL, Lew ED, Lazear HM, et al. The TAM receptor Mertk protects against neuroinvasive viral infection by maintaining blood-brain barrier integrity. Nat Med. 2015;21:1464-72. http://dx.doi.org/10.1038/nm.3974

39. Meertens L, Carnec X, Lecoin MP, Ramdasi R, GuivelBenhassine F, Lew E, et al.The TIM and TAM families of phosphatidylserine receptors mediate dengue virus entry. Cell Host Microbe. 2012;12:544-57. http://dx.doi.org/10. 1016/j.chom.2012.08.009

40. Miner JJ, Diamond MS. Understanding how Zika virus enters and infects neural target cells. Cell Stem Cell. 2016;18:55960. http://dx.doi.org/10.1016/j.stem.2016.04.009

41. Nowakowski TJ, Pollen AA, Di Lullo E, SandovalEspinosa C, Bershteyn M, Kriegstein AR. Expression analysis highlights $\mathrm{AXL}$ as a candidate Zika virus entry receptor in neural stem cells. Cell Stem Cell. 2016;18:591-6. http://dx.doi.org/10.1016/j.stem.2016.03.012

42. Dang J, Tiwari SK, Lichinchi G, Qin Y, Patil VS, Eroshkin AM, et al. Zika virus depletes neural progenitors in human cerebral organoids through activation of the innate immune receptor TLR3. Cell Stem Cell. 2016;19:258-65. http://dx. doi.org/10.1016/j.stem.2016.04.014

43. Hamel R, Dejarnac O, Wichit S, Ekchariyawat P, Neyret A, Luplertlop $\mathbf{N}$, et al. Biology of Zika virus infection in human skin cells. J Virol. 2015;89:8880-96. http://dx.doi. org/10.1128/JVI.00354-15
44. Chan JF, Yip CC, Tsang JO, Tee KM, Cai JP, Chik KK, et al. Differential cell line susceptibility to the emerging Zika virus: Implications for disease pathogenesis, non-vectorborne human transmission and animal reservoirs. Emer Micro Infect. 2016;5:e93.http://dx.doi.org/10.1038/emi.2016.99.

45. Bhattacharyya S, Zagórska A, Lew ED, Shrestha B, Rothlin, CV, Naughton J, et al. Enveloped viruses disable innate immune responses in dendritic cells by direct activation of TAM receptors. Cell Host Microbe. 2013;14:13647. http://dx.doi.org/10.1016/j.chom.2013.07.005

46. Rossi SL, Tesh RB, Azar SR, Muruato AE, Hanley KA, Auguste AJ, et al. Characterization of a novel murine model to study Zika virus. Am J Trop Med Hyg. 2016;94:1362-9. http://dx.doi.org/10.4269/ajtmh.16-0111

47. Onorati M, Li Z, Liu F, Sousa AM, Nakagawa N, Li M, et al. Zikavirus disrupts phospho-TBK1 localization and mitosis in human neuroepithelial stem cells and radial glia. Cell Rep. 2016;16:2576-92. http://dx.doi.org/10.1016/j.celrep. 2016.08.038

48. Tabata T, Petitt M, Puerta-Guardo H, Michlmayr D, Wang C, Fang-Hoover J, et al. Zika virus targets different primary human placental cells, suggesting two routes for vertical transmission. Cell Host Microbe. 2016;20:155-66. http://dx. doi.org/10.1016/j.chom.2016.07.002

49. Shao Q, Herrlinger S, Yang SL, Lai F, Moore JM, Brindley MA, et al. Zika virus infection disrupts neurovascular development and results in postnatal microcephaly with brain damage. Development. 2016;143:4127-36. http://dx. doi.org/10.1242/dev.143768

50. Cao-Lormeau VM, Blake A, Mons S, Lastère S, Roche C, Vanhomwegen J, et al. Guillain-Barré syndrome outbreak associated with Zika virus infection in French Polynesia: A case-control study. Lancet. 2016;387:1531-9. http://dx.doi. org/10.1016/S0140-6736(16)00562-6

51. Coffey JC, McDermott KW. The regional distribution of myelin oligodendrocyte glycoprotein (MOG) in the developing rat CNS: An in vivo immunohistochemical study. J Neurocytol. 1997;26:149-61.

52. Gold R, Hartung HP, Toyka KV. Animal models for autoimmune demyelinating disorders of the nervous system. Mol Med Today. 2000;6:88-91.

53. Pettersson JH, Eldholm V, Seligman SJ, Lundkvist Å, Falconar AK, Gaunt MW, et al. How did Zika virus emerge in the Pacific Islands and Latin America? MBio. 2016;7:e01239-16. http://dx.doi.org/10.1128/mBio.01239-16.

54. Richard AS, Shim BS, Kwon YC, Zhang R, Otsuka Y, Schmitt K, et al. AXL-dependent infection of human fetal endothelial cells distinguishes Zika virus from other pathogenic flaviviruses. Proc Natl Acad Sci USA. 2017. pii: 201620558. http://dx.doi.org/10.1073/pnas.1620558114

55. Tang H, Hammack C, Ogden SC, Wen Z, Qian X, Li Y, et al. Zika virus infects human cortical neural progenitors and attenuates their growth. Cell Stem Cell. 2016;18:587-90. http://dx.doi.org/10.1016/j.stem.2016.02.016 